\title{
On the Development and Tendency of Chinese Internet Finance
}

\author{
Sun Yanli \\ Weifang University \\ Weifang, Shandong Province, China
}

\begin{abstract}
Over the past 20 years, the Internet has started from scratch, from slow to rapid development in China, and not it has gradually extended from the daily application sector to the financial sector. As commanding height of the entire financial innovation, Internet finance (ITFIN) has worked as the innovative financial model to rebuild functions such as the financial payment mode, informational processing and resource allocation and raise the fund accommodation and financial service efficiency based on big data, cloud computing and mobile Internet technologies. This article briefly analyzes the development of ITFIN business in China, including Internet payment, financial products, $P 2 P$, crowd-funding and Internet securities as well as insurance, and then forecast the future developing tendency of the main ITFIN forms and elements such as mobile Internet payment, P2P lending and crowd-funding in China.
\end{abstract}

Keywords-Internet Finance (ITFIN), P2P lending, Crowdfunding, Tendency

\section{TIME BACKGROUND OF INTERNET FINANCE (ITFIN)}

In nowadays society, the Internet has become an integral part of people's lives. The rise of mobile Internet and the application of technologies such as mobile payment and twodimensional code to provide users with simple and effective connectivity, allow users to break the time and geographical limitations and ensure that they can conduct activities anytime and anywhere. For example, Didi Chuxing. With the application this simple App, passengers could be directly connected with taxi drivers. A few months later, it has captured the hearts of hundreds of millions of users and made the original phone call platform reduce to be a decoration. YY education has invested 1 billion Yuan into the online education platform, aiming at fighting against the traditional education institutions. Catering $\mathrm{O} 2 \mathrm{O}$ has crossed the online and offline borders and rebuilt the public dining habits from the popularity of Dianping 10 years ago to the rise of group purchase in the current 3-4 years and then the prevailing of the takeaway delivery App recently.

Internet has significantly stenciled its brand on the car rental and taxi calling, training and education together with catering services, the Internet economy has gradually revealed its unique technical characteristics and operation mode. The large-scale penetration of the Internet industry has triggered its integration with the financial industry. Instead of merely

This paper is funded by staged research results of 2017 Shandong Social Sciences Planning Fund Project Finance Project "Research on Sustainable Development of Precision Poverty Alleviation in Shandong Province from the Perspective of Finance Sharing" (17CJRJ09), Postdoctoral Research Center Station, School of Economics of Shandong University. serving as the tool to reduce the operating costs for the traditional financial institution, Internet has gradually introduced its own spirit of "equality, openness, cooperation and sharing" to the traditional financial industries. And the invention, expansion and commercialization of mobile payments, social networks, search engines and cloud computing technologies in particular have had a fundamental impact on the innovation of global financial models.

ITFIN is the emerging sector integrated by the traditional financial industry and the Internet industry. From the broad sense, any Internet applications such as Internet investment and financing, Internet payment, financial intermediation, credit collection and evaluation, risk control concerning the finance should belong to ITFIN. When it comes to the narrow sense, ITFIN refers to the credit circulation of currency relying on the Internet. At present, Internet finance has touched the core of the traditional financial industry in terms of payment mode, profit model, information processing and resource allocation which not only brings about the transformation of people's financial philosophy, but also results in tremendous changes in people's financial management, payment and financing to negatively affect the traditional financial institutions.

\section{INTEGRATION AND REBUILDING OF INTERNET TO TRADITIONAL FINANCIAL INDUSTRY}

\section{A. ITFIN started by Internet Payment}

2013 has been known as "First Year of Chinese Internet Finance" during which Yu'e Bao embedded in Alipay has come into being. By the end of 2013, it has taken in up to 250 billion Yuan in just a few months. What's more, Tianhong Asset Management, an unknown third-rate fund, has jumped leaped in the first echelon of entire fund sector with its capital scale ranking the second in 2013 and almost going beyond China Asset Management, the flagship of whole industry. After Yu'e Bao, three giants have dabbled in various "Bao", namely Internet financing products, with the annual rate for up to 7-8\%. And the essence of such kind of sales of ITFIN is to bring convenience to the purchasing. As for how much the return would be, no one could give the clear answer. However, until now, no financing product could have over $7 \%$ return rate. The sales of Internet financial product has been aiming at the lowend users. The real wealthy people would think the return rate of such products is a little bit low. People with over 100 thousand spare cash would buy certain financing products. People with over million spare cash shall talk about deposits 
agreement with banks whose minimum yield would surpass all kinds of "Bao". In fact, majority of earnings coming from the monetary fund behind these "Bao" are the difference between the annualized interest rate and the agreement deposits, in other words, it just like earning the wholesale and retail price differentials.

\section{B. $P 2 P$ is the ITFIN with Real Vitality}

$\mathrm{P} 2 \mathrm{P}$ is the bridge between the common users and SMEs and it is also the application of the Internet in real sense which enables the Internet factor infiltrate into the corporate finance. The so-called full-scale penetration of the Internet to the enterprise should be an important dimension. Although the current general scale of $\mathrm{P} 2 \mathrm{P}$ is much smaller than that of the Internet financial products, but its future does worth far more expectation. The trends reflected in certain policies shall present the opinion of administrative authorities to P2P. For example, the Supreme People's Court has adopted a judicial interpretation to sort out and define the "illegal fund-raising crime", which would bring much benefit to P2P because the crime of illegal fund-raising is a serious policy risk. As this charge being cleared, P2P will be boosted. In a macro sense, $\mathrm{P} 2 \mathrm{P}$ is more economical than all kinds of "Bao" because P2P can effectively solve the capital needs of a large number of SMEs. Small and medium-sized enterprises (SMEs) have made up a great proportion of the overall national economy and served as an important part with much attention from the country. Under such circumstance, to help them solve their funding requirement does conform to the national interest.

However, P2P does not develop as right as rain domestically and even if the large enterprises such as Credit Ease would have certain rumors for their hundreds of millions of bad debts, let alone the news about bankruptcy of P2P platform or the escape of their boss. The observation and research to the qualification of $\mathrm{P} 2 \mathrm{P}$ platform have also become an information requirement. The difficulty of P2P lies in the business credit, only if this part turns to be sound, would the entire investment be more secure. Ali small loans for Taobao businesses (it is not P2P, but the small loan business), has dealt with credit issues without too much difficulties. Ali small loan business has made use of its own Taobao Tmall platform to cleverly solve the creditability of the mortgage lenders who do not have many assets, and use their day-day account to control the risk of bad debts. Ali small loan has already found some breakthroughs in the "loan" link.

\section{Crowd-funding is the Third Direction for ITFIN}

In 2009, crowd-funding site Kickstarter has come into being in the United States been popular worldwide rapidly. On this platform, anyone can send his idea of starting a business to this website and publish it after being audited by the website. Later, net friends would give the financial support voluntarily and their return is the corresponding product or service. Crowd-funding sites would draw a percentage of commissions from successful projects. The popularity of Kickstarter and its crowd-sourcing model around the world have attracted the attention of the domestic Internet community. A large number of crowd-funding websites such as Dreamore, Zhongchou, Ctquan and AngelCrunch have emerged. At present, limited by the policy factors, the domestic crowd-funding has still adopted the pre-sale model on their products. A small niche project called "Vinyl Record Player" raised millions of dollars in 20 days has been known as a miracle in the crowd-funding program because its promoter was not a celebrity without too much appeal. But it is still a sales activity, not a financial act. In China, it might be difficult for the crowd-funding to have great breakthrough in the short term. The operating process of a well-known domestic crowd-funding platform AngelCrunch shall be like this: (1) investors settle in the platform; (2) entrepreneurs submit projects online; (3) professional analyst team of AngelCrunch reviews the project; (4) investors browse the project and AngelCrunch recommend the program to investors; (5) entrepreneurs and investors talk with each other; (6) entrepreneurs and investors sign the agreement. The first and second points sound like having something to do with the Internet, but the following steps shall be done offline later. Although AngelCruch has claimed to be a crowd-funding organization, it still just make use of the Internet to solicit programs which seems have nothing different from the venture capital and angel investment in general.

\section{Promote the Revolution in Security and Insurance Market}

Monetary fund has borne the brunt of the stock market in which Internet companies are involved. Internet companies combine the investment value, liquidity, and payment function and user experience of the Monetary Fund to create a powerful cash management tool to build a capital reservoir fighting for the “deposit movement”. For example, on October 28, 2013, a newly increased money fund of the first financing product "Baifa" under Baidu Finance based on the cooperation of Baidu and China Asset Management has gone online with more than 1 billion Yuan in sales covering more than 120,000 users. Similarly, Internet companies are also trying to get involved in the insurance industry. On November 6, 2013, Zhong An Online Property Insurance Co., Ltd., the first Internet insurance company in China, opened in Shanghai. Zhong An Insurance Co., Ltd. has been established by Alibaba, Tencent and China Ping An Insurance jointly with the registered capital of 1 billion Yuan and its main business includes business / family property insurance, cargo insurance and liability insurance. In general, this company has operated around three directions, namely e-commerce, mobile payment and the Internet Finance.

\section{DeVElOPMENT TENDENCY Vista OF CHINESE MAIN INTERNET FINANCIAL FORM}

\section{A. Rapid Growth of Mobile Internet Payment}

In the mid and late 2014, Apple Pay, the mobile payment tool introduced by Apple, became an iconic product of mobile payment innovation. In our country, both the remote payment focused by Alipay and the near-field payment focused by WeChat have made a profound impact on the traditional retail payment system pattern, which presenting the greater potential threat to the traditional card payment medium. At the same time, the rise of mobile payment also prospers mobile money management and mobile wealth management. In the long run, mobile Internet payments will show up as more cutting-edge 
innovations as the PC internet payment model impacts the traditional financial system. When it comes to the retail payment system structure, as the bank entering into the background, the phenomenon that payment institutions embarking on the foreground seems to be the result of market development and the division of labor, rather than the technical advantages. Therefore, at present, banks have made great efforts to innovate in mobile payment and tried to compete for capital entrance. Of course, this will be conducive to the development of mobile payment itself, but it may still fail to affect the market structure ultimately. Compared with banks, payment agencies can make better use of big data to provide value-added services, make it easier to coordinate the flow of funds, logistics and customer information, and have the flexibility to adjust according to change. Under the trend of deepening the labor division, for banks, in addition to trying to compete for retail mobile payment terminals, the question such as how to deal with the marketization of interest rates and the transformation of business models should be taken into consideration in advance.

\section{B. Value Regression of P2P Lending}

The real value of P2P lending is to, firstly, serve the financing of small and micro enterprises and individual entrepreneurship, secondly, provide abundant investment products to residents, thirdly, increase credit building and information accumulation in financial transactions, fourthly, promote the private financing under the "virtual" sunshine. So far, P2P lending has been attractive in attracting investment, but it still has certain deficiencies in other fields. If left unmanaged, it will inevitably become the hardest hit area where Internet financial risks would break out in a concentrated way. To understand and respond to $\mathrm{P} 2 \mathrm{P}$ lending rationally, it is rather necessary to return to the essence of private financing. Under the framework of separation regulation, according to the logic of institutional regulation, more and more emerging financial organizations, including $\mathrm{P} 2 \mathrm{P}$, cannot be kept under control. In this case, transferring from institutional regulation to functional regulation turns to be the key to solve this type of conflict. Operating "information" rather than "funds" is the business nature and positioning of $\mathrm{P} 2 \mathrm{P}$ lending which requires that information interaction, revealing, transparency and evaluation should be regarded as the core in the course of regulation and return to its securities regulation-oriented characters in most countries and promote the drawn-out of private direct lending game rules. And the capital pool, selffinancing and self-use platforms criticized by regulatory authorities obviously belong to the privately-funded indirect financing body whose risk control and market regulation should refer to the access and supervision of such financial organizations.

\section{Promote Crowd-funding to be the Experimental Field for Micro-Finance}

From the English word of Crowdfunding, its original intention is to raise money from the general public, namely, club together. But the difference between this type of fundraising and the traditional one is that it is conducted through the Internet platform which not only makes it easier to centralize the scattered funds, but also provides a mechanism that is more flexible than the traditional venture capital. Like other financial models that serve capital allocation, crowd funding involves three main actors: fund providers, capital demanders, and financial intermediaries. First, from the perspective of fund providers, equity crowd funding requires, to a certain degree, investors' ability to discriminate and afford the risk of investment projects, especially in China, and should not only avoid to be socialized or popularized in the short term, but also should insist the proper threshold for investors during which strengthening the protection to financial consumers is the most important link. Second, judging from the demanders for funds, the fundamental objective of crowd funding is to insist on "small and beautiful", that is to say to serve for the financial needs of small and micro enterprises. The difficulty in financing of small and micro enterprises has always been a global problem. Even in such a developed financial system as the United States, there is a "blank area" in financial support. It could be concluded that the reasonable positioning of China's crowd funding development is still the grassroots financial component of the multi-level capital market, rather than the large-scale and medium-term needs of funds in real estate and industrial projects. Third, from the financial intermediary point of view, considering the nature of financial service provided by the intermediary platform such as equity crowd funding, the specific industrial or license constraints should be given accordingly.

\section{CONCLUSION}

In a word, the Internet financial will behave more depth and breadth, Internet financial will permeate to the more traditional industries, booster industry transformation and upgrade.By participating in Internet financial activities, residents' deposits will gradually become less, funds through various channels to direct financing mode, it is the trend of the future.

\section{REFERENCES}

[1] Yang Tao, Chen Lian. Theory and Practice of Internet Finance [M]. Beijing: Economy and Management Publishing p House, 2015: 283-286.

[2] Li Xuejing. Development and Future of Crowd-Funding [J]. Journal of Shanghai Finance University, 2013(6).

[3] Wang Yimin, Wangjin. Research on the Development of Network Lending in Chinese Practice [J]. Huabei Finance, 2011(2).

[4] Yu Laiwen, Wen Zhubing, Bian Junjie, Shilei. Online Finance: The Integration of Crossboarder, Crowdfunding and Big Data [M]. Beijing: Economy and Management Publishing p House, 2015: 21. 